\title{
Feeding practices and factors associated with the provision of iron-rich foods to children aged 6-23 months in Matam area, Senegal
}

\author{
Kossi Akpaki ${ }^{1 * *} \odot$, Isabelle Galibois ${ }^{1}$ and Sonia Blaney ${ }^{2}$ \\ 'School of Nutrition, Laval University, Pavillon Paul-Comtois, 2425 Rue de l'Agriculture, Quebec City, QC G1V OA6, \\ Canada: ${ }^{2}$ School of Food Sciences, Nutrition and Family Studies, Moncton University, Moncton, NB, Canada
}

Submitted 13 January 2021: Final revision received 2 June 2021: Accepted 18 June 2021: First published online 24 June 2021

\begin{abstract}
Objective: The objectives of this study were to document feeding practices amongst rural Senegalese children aged 6 to 23 months and to investigate psychosocial and environmental factors associated with the provision of iron-rich foods (IRF).

Design: This was a cross-sectional study conducted from January to July 2018.

Setting: The study took place in the region of Matam, northern Senegal.

Participants: Ninety-eight mothers of children aged 6-23 months.

Results: Results show that $27.6 \%$ of children were fed according to the minimum acceptable diet, and $55.1 \%$ and $53.1 \%$ had the minimum diet diversity and minimum meal frequency, respectively. About $65.3 \%$ of mothers provided IRF to young children the day before the survey, mostly fish. Mother's intention to provide IRF to their children was not associated with the provision of these foods neither was the perceived behavioural control. Child's age (OR $=1 \cdot 14,95 \% \mathrm{CI}$ (1.03, 1.26), $P=0.012)$ and household food insecurity score (OR $=0.80,95 \%$ CI $(0.68,0.96), P=0.014)$ were the predictors of the provision of IRF to children aged 6-23 months.

Conclusions: Household food insecurity status and age of the child rather than mothers' psychosocial factors were significant predictors of IRF consumption amongst children aged 6-23 months in the study area. More attention should be given to food environment and child-related factors in order to improve children feeding practices and, in particular, their consumption of IRF in the study setting. For instance, home visits and the 5-month-old vaccine consultation in health centres might be opportunities to reinforce the importance of providing IRF as part of complementary foods from the age of 6 months. Implementation of measures for the improvement of socio-economic conditions and food security of households would also be valuable.
\end{abstract}

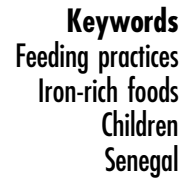

Worldwide, Fe deficiency anaemia remains a major public health issue especially in sub-Saharan Africa where more than $60 \%$ of children under 5 years of age are anaemic ${ }^{(1)}$. Consequences of anaemia in early life are severe and have been largely documented ${ }^{(2)}$. In young children, anaemia has an impact on their cognitive development, may damage their immune system, and has been associated with increased morbidity rates ${ }^{(2)}$. Senegal is amongst the countries with the highest prevalence of anaemia which affects $71 \%$ of children under 5 years of age ${ }^{(3)}$. National data show that the nutrition situation amongst young children of the Matam region, northern Senegal, is one of the worst of the country: this area has the highest rate of wasting among children under 5 years of age and about $75 \%$ are anaemic $^{(3)}$.

According to the UNICEF framework on determinants of young child nutritional status, food security and care practices such as feeding practices are the underlying factors of child dietary intake, one of the immediate causes of malnutrition ${ }^{(4)}$. Moreover, it is well acknowledged that an adequate diet is of crucial importance for optimal child nutrition and development, especially in the first 2 years of life ${ }^{(5,6)}$, hence underlying the need to improve care practices and food security.

Food security is achieved 'when all people, at all times, have physical and economic access to sufficient, safe and 
nutritious food to meet their dietary needs and food preferences for an active and healthy life ${ }^{(7)}$. Evidence shows that household food security has been positively associated with young child feeding practices, and that in food-insecure areas, the provision of adequate child diet may be jeopardised if households have limited access to foods ${ }^{(4)}$. In addition, care practices defined as the provision of time, attention and support to children by the mothers/ caregivers include breast-feeding, complementary feeding and food preparation, as well as psychosocial care, hygiene and health practices are $\mathrm{critical}^{(8)}$. Current data show that amongst children aged 6-23 months living in low- and middle-income countries, feeding practices are not optimal. Indeed, at the global level, three out of ten children aged 6-8 months do not receive complementary foods and eight out of ten do not benefit from the minimum acceptable diet $(\mathrm{MAD})^{(9)}$.

Food security and care practices are also interrelated ${ }^{(4)}$. Indeed, access to food, which is a component of food security, has a direct impact on children's food intake in addition to influencing mothers' behaviour regarding feeding practices. To design effective nutrition programmes, it is essential to get a good understanding of the relationship between feeding practices, food security and factors underlying mothers' behaviour.

To our knowledge, no study has been undertaken in the Matam area to assess the aforementioned relationship, despite of available data painting a grim picture of household food security and young child feeding practices in this region. In 2014 , only $13 \%$ of households were food-secure ${ }^{(10)}$ and data from 2018 Demographic and Health Survey (DHS) indicate that $7 \%$ of children aged 6-23 months were fed with the $\mathrm{MAD}^{(3)}$, while about $50 \%$ had consumed iron-rich foods (IRF) in the past $24 \mathrm{~h}^{(3)}$. This situation is worrisome given the high rate of anaemia amongst this age group $^{(11,12)}$.

To investigate factors that may impact the provision of IRF to young children, a study was initiated amongst a group of households with children aged 6-23 months in the Matam area. Our previous findings have shown that $64 \%$ of these households were severely food-insecure ${ }^{(13)}$. Results have also revealed that food availability at the community and household level as well as the household socio-economic status were associated with household food insecurity ${ }^{(13)}$. Mothers' psychosocial factors have also been explored to acquire some understanding of what could affect their intention to provide IRF to their children (unpublished results). Results have shown that a vast majority of mothers had a strong intention to provide IRF daily to their children. Having a positive attitude and a favourable perception of the subjective norm (SN) were also both associated with a higher intention to provide IRF to young children (unpublished results). Nevertheless, in this context, having a strong intention may not be a sufficient condition for the implementation of the behaviour $^{(3)}$.
The paper aims to investigate the relationship between the consumption of IRF amongst children aged 6-23 months, mother's psychosocial factors, household food security status and sociodemographic characteristics. An extended version of the Theory of Planned Behaviour (TPB) ${ }^{(14)}$ was used to guide the assessment as it combines individual and environmental factors that determine a behaviour. The situation on core infant and young child feeding (IYCF) practices ${ }^{(15)}$ was also assessed to have a comprehensive overview of their quality in our population.

\section{Methods}

\section{Theoretical framework: extended version of Theory of Planned Behaviour}

An extended version of the TPB ${ }^{(14)}$ was used as the theoretical framework to identify predictors of the behaviour under study, which was the provision by mothers of IRF to their children aged 6-23 months. According to the $\mathrm{TPB}$, the intention of a person to either perform or not perform a behaviour is the first determinant of the behaviour. A person's intention represents his/her motivation towards the adoption of a behaviour, and it is itself determined by three constructs: the attitude towards the behaviour (ATT), the $\mathrm{SN}$ and the perceived behavioural control $(\mathrm{PBC})^{(16)}$.

ATT is determined by a person's beliefs about the behaviour (behavioural beliefs) and his/her evaluation of the consequences of adopting it (consequences evaluation). It is a subjective judgement of the behaviour and its consequences ${ }^{(16)}$.

$\mathrm{SN}$ is determined by the importance a person gives to the opinions of people or groups of people around him/her (normative beliefs) and by the motivation to follow these opinions (motivation to comply) ${ }^{(16,17)}$.

PBC is determined by the degree of control a person believes he/she can exercise over a given behaviour (control beliefs) and by the perception of ease or difficulty (perceived power of control factors) with which behaviour can be adopted ${ }^{(17)}$. According to the theoretical framework, PBC measures a person's sense of self-efficacy about the behaviour but it can also directly predict the behaviour $^{(16,17)}$. Consequently, intention and $\mathrm{PBC}$ are the ultimate predictors of the behaviour, whereas the effect of ATT and SN on behaviour is mediated through the intention $^{(16)}$.

Thus, in the present study, only the mothers' intention and $\mathrm{PBC}$ were the original TPB constructs tested as predictors of the behaviour under study. As suggested for an extended TPB, the influence of external factors that may impact individual behaviour was also taken into account in the theoretical framework ${ }^{(14)}$. External factors are of two types: personal factors and environmental factors. External factors may influence a behaviour in two ways: (a) mediation, where external factors' influence over the behaviour is through the individual psychosocial factors 
of the TPB and (b) moderation, where external factors' influence is through the relation between intention and behaviour $^{(14)}$.

\section{Study design and setting}

The research design and setting have been described previously ${ }^{(13)}$. This was a cross-sectional study conducted in four villages located in the region of Matam, which is the second-largest region and one of the poorest in Senegal. The landlocked position, irregular rainy seasons and resulting critical economic situation have made the Matam region one of the most vulnerable in the country as regards food and nutrition security ${ }^{(18)}$.

\section{Sampling}

As described previously, the original sample under study comprised 103 households with children aged 6-23 months ${ }^{(13)}$. The sample size was determined with the $G$ * Power software ${ }^{(19,20)}$ taking into account the number of factors (five) included in the theoretical framework that predict the behaviour under study (i.e. giving IRF to children aged 6-23 months on a daily basis), a significance level $(\alpha)$ of $5 \%$, a statistical power of $80 \%$ and a medium effect size of $0 \cdot 15$. A non-response rate of $10 \%$ was considered for the calculation of the final sample size. In short, in two departments (Matam and Kanel) out of the three comprised in the Matam region, one municipality was randomly chosen, and, in each municipality, two villages were also randomly selected. In each village, 25 or 26 households were randomly chosen ${ }^{(13)}$.

\section{Data collection}

The data collection was conducted from January to July 2018.

Environmental factors: housebold food insecurity status and child, bousebold and community characteristics

Household food insecurity status was assessed using the Household Food Insecurity Access Scale Questionnaire ${ }^{(13,21)}$. Data were collected through an individual interview conducted at home with the mother of each child aged 6-23 months ${ }^{(13)}$. On this occasion, the number of foods available at the household level was assessed via direct observations. Questions were also asked about ways of food acquisition (production, trade, donation or purchase) by the household ${ }^{(13)}$.

Moreover, the number of foods available at community level was collected through direct observations of foods sold in local shops and public market ${ }^{(13)}$. Observations were followed by focus group discussions (FGD) conducted in every village with mothers and heads of households separately to gather information on food availability throughout the year ${ }^{(13)}$.

Using an adapted version of the Senegal DHS questionnaire, data were collected on household composition (age and gender of the child, age and education level of the head of household and the child's mother, gender of the head, and household size), housing conditions and ownership of assets through an interview with the head of household ${ }^{(13)}$.

\section{Mother's psychosocial-related factors}

Based on the TPB, a questionnaire with pictograms was developed according to the approach described by Gagné and Godin ${ }^{(22)}$ and the methodological recommendations of Ajzen ${ }^{(23)}$.

First, FGD were conducted with a subsample ( $n$ 50) of mothers from the four selected villages to identify salient beliefs related to the daily provision of IRF to their children aged 6-23 months. During FGD, mothers were asked to express their beliefs about the following: (1) advantages and disadvantages of giving IRF daily to their children aged 6-23 months (ATT); (2) persons or groups of persons who would approve or disapprove the behaviour under study (SN) and (3) opportunities and barriers to implement the behaviour (PBC). Based on Rabiee's recommendations ${ }^{(24)}$, a qualitative analysis of the FGD was conducted by the first author of the manuscript (K.A.) to identify salient beliefs related to each of the three constructs (ATT, SN and PBC).

Afterwards, salient beliefs were used as the primary source for the formulation of an initial questionnaire which included a total of sixty-seven items: (a) intention: three items; (b) ATT: eleven items were formulated to assess behavioural beliefs and nine items to assess the evaluation of consequences; (c) SN: sixteen items to assess normative beliefs and sixteen items on the motivation to comply with these beliefs; and (d) PBC: eight items to assess control beliefs and four items on the perceived power over the behaviour.

Graphic answer scales using pictograms of angry/smiley faces were used for all items of the questionnaire. Pictures of angry/smiley faces in the upper part of the graphic scale were provided by the London School of Tropical Medicine and Hygiene; pictures used to illustrate the five answer options of the Likert scale (faces with hands on the mouth, thumbs up and thumbs down) were found on the internet.

For validation purposes, the 67-item questionnaire was administered to 120 mothers of children aged 6-23 months recruited in 2 villages of the Matam region (other than the 4 villages of the main study). Before administrating the questionnaire, the interviewer explained to each participant how to express answers to questions on each scale. Regarding the five-answer options scale with pictograms, the interviewers first explained that the two extreme opposite pictograms (an angry face at the far left and a smiley face at the far right of each scale) reflected bipolar adjectives that could mean, depending on the formulation of the question or statement read by the interviewer, answers such as " disagree/agree " or " not important/ important ". Following the explanation of each scale, the interviewer administrated the questionnaire, reading item 
by item and asking the participant to put her finger on or to mark with a pen the selected answer on each respective scale.

After data entry, principal component analyses were run to reduce the number of items under each construct while still respecting the assumptions for sampling adequacy (having a Kaiser-Meyer-Olkin/KMO value $>0.70$ ) and ensuring that correlations between items were strong (Bartlett's test $<0.05)^{(25)}$. For each construct, an exploratory factor analysis was thereafter conducted on the final model using an orthogonal rotation (varimax). The reliability was assessed using the Guttman test ${ }^{(26,27)}$.

The principal component analyses led to the final questionnaire with the required KMO values for the ATT (twelve items), SN (sixteen items) and PBC (ten items) constructs. Regarding intention, one item was removed from the final questionnaire. Finally, a last exploratory factor analysis combining all items (including final two items for the measurement of intention) showed that the above assumptions and reliability were respected. This final questionnaire (English-translated version available in online supplemental material) which included forty items was administered to mothers of 6-23-month children in participant households of the main study.

\section{Infant and young child feeding practices}

Data on core IYCF practices, including the provision of IRF, were collected through the IYCF module of the household questionnaire used in the Senegal $\mathrm{DHS}^{(3,15)}$. The module was administered to the child's mother during an individual interview at her home. Specifically, data were collected on the child's breast-feeding status, his/her age of introduction of solid, semi-solid or soft foods, as well as on meal frequency, dietary diversity and his/her consumption of Fe-rich or Fe-fortified foods yesterday during the day or at night.

\section{Data analysis}

\section{Environmental factors}

Each household was assigned a score on its food insecurity level. The score was computed by summing households' scores for each of the nine questions; the minimum household food insecurity score was 0 and the maximum was 27 , given that for each question, the score ranged from 0 to 3 . A higher score reflects a greater household food insecurity ${ }^{(21)}$. Furthermore, households were categorised as being food-secure or mildly, moderately or severely food-insecure according to the classification method of Coates and colleagues ${ }^{(21)}$.

For the numbers of foods available at the community and household levels, the total numbers of food recorded in each case was used as a continuous variable. Finally, using data of household ownership of assets and housing conditions, a factor analysis was conducted to define a socio-economic score which was assigned to each household ${ }^{(13)}$.

\section{Mother's psychosocial factors}

For all items of the questionnaire on mothers' psychosocial factors, the five answer options were scored from 1 to 5 or from 5 to 1 in case of inverted item formulation. A mean score on the intention of the mother to provide IRF daily to her child aged 6-23 months was calculated by averaging scores of the two items. Concerning ATT, SN and PBC constructs, a mean score (possible maximum of 5) was first calculated for each mother for each of the two sub-related constructs: behavioural beliefs (eight items) and evaluation of consequences (four items) for ATT; normative beliefs (eight items) and motivation to comply (eight items) for $\mathrm{SN}$; and control beliefs (six items) and perceived power of control factors (four items) for PBC, respectively. Thereafter, for each mother, a score on each construct (ATT, SN and PBC) was calculated by multiplying the mean scores of its respective two subconstructs, for a possible maximum of 25 .

\section{Infant and young child feeding practices}

The consumption of IRF was analysed using WHO guidelines ${ }^{(15,28)}$. In the context of this study, IRF included meat, poultry, liver/organ meats, fish/seafood, but also eggs $^{(3)}$ to compare our results to the national data. If the child had consumed any of the IRF in the day preceding the survey, a value of one (1) was assigned to him/her and a value of zero $(0)$, if not.

In addition to the aforementioned feeding practices, for each child, IYCF practices were assessed using the following core indicators ${ }^{(15)}$.

Continued breast-feeding at 1 year was computed by calculating the proportion of children 12-15 months of age who were fed with breast milk during the day before the survey.

Introduction of solid, semi-solid or soft foods was computed by calculating the proportion of infants 6-8 months of age who received solid, semi-solid or soft foods the day before the survey.

Minimum dietary diversity (MDD) was computed by calculating the proportion of children aged 6-23 months who received foods from at least four of the following seven food groups: (1) grains, roots and tubers; (2) legumes and nuts; (3) dairy products (milk, yogurt, cheese and infant formula); (4) flesh foods (meat, fish, poultry and liver/organ meats); (5) eggs; (6) vitamin A-rich fruits and vegetables; and (7) other fruits and vegetables ${ }^{(15)}$.

Minimum meal frequency (MMF) was computed by calculating proportions of breastfed and non-breastfed children aged 6-23 months who received solid, semi-solid or soft foods (also including milk feeds for non-breastfed children) the minimum number of times or more. For breastfed children, the minimum number of times varies with age: two times if 6-8 months old and three times if 9-23 months old, while for all non-breastfed children aged 6-23 months, the minimum number of times was four times. 
MAD was determined by calculating the proportion of children who met criteria for both MDD and $\mathrm{MMF}^{(15)}$.

\section{Statistical analyses}

Statistical analyses were performed with the IBM SPSS Statistics for Windows, Version 23.0. (IBM Corp.).

Descriptive statistics, mostly means and standard deviation or frequency distributions, were performed on all variables measured in this study. Chi-square tests with a level of significance set at $P$-value $<0.05$ were used to check the effect of different factors on proportions of children who consumed the various food groups (Table 1) and on proportions of children benefiting from the MDD, MMF and MAD feeding practices (Table 2). Also, chi-square tests were used to assess differences in proportions between characteristics with regard to the provision of IRF to identify potential predictors of the aforementioned behaviour under study (Table 3). Multi-level binary logistic regression analyses were conducted to identify predictors of the provision of IRF to children, based on the extended version of the TPB in which candidate external factors had been predetermined (Fig. 1). OR and $95 \%$ CI were determined for all regressions. In bloc 1 , a potential confounding external factor (age of the child) was entered, followed in bloc 2 by the food environment variables (number of foods available at community and household level and ways of food acquisition). In bloc 3, only household food insecurity score was entered, and finally, the intention and the PBC were entered in bloc 4. A $P$-value $<0.05$ was used as the criterion for statistical significance for the final model. The final model fit was assessed using the overall model

Table 1 Proportions (\%) of children aged 6-23 months who consumed foods from each of the seven food groups* $(n 98)$

\begin{tabular}{|c|c|c|c|c|c|c|c|c|}
\hline \multirow[b]{2}{*}{ Characteristics } & \multirow[b]{2}{*}{$n$} & \multicolumn{7}{|c|}{ Foods groups } \\
\hline & & $\begin{array}{c}\text { Grains, roots and } \\
\text { tubers }\end{array}$ & $\begin{array}{l}\text { Legumes and } \\
\text { nuts }\end{array}$ & $\begin{array}{l}\text { Dairy } \\
\text { product }\end{array}$ & $\begin{array}{l}\text { Flesh } \\
\text { foodst }\end{array}$ & Eggs & $\begin{array}{l}\text { Vit. A-rich vegetables } \\
\text { and fruits }\end{array}$ & $\begin{array}{l}\text { Other fruits and } \\
\text { vegetables }\end{array}$ \\
\hline \multicolumn{9}{|c|}{ Age (months) of breastfed children } \\
\hline $6-11$ & 33 & $75 \cdot 8$ & $6 \cdot 1$ & 54.5 & $48 \cdot 5^{\star \star}$ & $12 \cdot 1$ & $69 \cdot 7$ & $30 \cdot 3$ \\
\hline $12-17$ & 36 & $83 \cdot 3$ & $19 \cdot 4$ & 63.9 & $72 \cdot 2$ & $8 \cdot 3$ & $83 \cdot 3$ & $16 \cdot 7$ \\
\hline $18-23$ & 11 & $72 \cdot 7$ & $18 \cdot 2$ & $63 \cdot 6$ & $72 \cdot 7$ & 0.0 & $72 \cdot 7$ & 9.1 \\
\hline $6-23$ & 80 & $78 \cdot 8$ & $13 \cdot 8$ & $60 \cdot 0$ & $62 \cdot 5$ & $8 \cdot 8$ & $76 \cdot 3$ & $21 \cdot 3$ \\
\hline \multicolumn{9}{|c|}{ Age (months) of non-breastfed children } \\
\hline $12-17$ & 3 & $100 \cdot 0$ & 0.0 & $66 \cdot 7$ & $66 \cdot 7$ & 0.0 & $100 \cdot 0$ & $33 \cdot 3$ \\
\hline $18-23$ & 15 & $86 \cdot 7$ & $26 \cdot 7$ & $80 \cdot 0$ & $80 \cdot 0$ & 13.3 & $80 \cdot 0$ & $20 \cdot 0$ \\
\hline $6-23$ & 18 & $88 \cdot 9$ & $22 \cdot 2$ & $77 \cdot 8$ & $77 \cdot 8$ & $11 \cdot 1$ & $83 \cdot 3$ & $22 \cdot 2$ \\
\hline \multicolumn{9}{|l|}{ All children } \\
\hline $6-23$ & 98 & $80 \cdot 6$ & $15 \cdot 3$ & $63 \cdot 3$ & $65 \cdot 3$ & $9 \cdot 2$ & $77 \cdot 6$ & $21 \cdot 4$ \\
\hline
\end{tabular}

*Based on WHO/UNICEF recommendations ${ }^{(15)}$.

†Meat, fish, poultry and liver/organ.

${ }^{\star *}$ Significant differences $(P<0.05)$ in proportions between age groups using Pearson's chi-square test.

Table 2 Proportions (\%) of children fed according to the three IYCF feeding practices* by background characteristics ( $n 98)$

\begin{tabular}{|c|c|c|c|c|}
\hline Characteristics & $n$ & MDD & MMF & MAD \\
\hline \multicolumn{5}{|l|}{ Age of the child (months) } \\
\hline $6-11$ & 33 & $36 \cdot 4^{\star *}$ & $45 \cdot 5$ & $21 \cdot 2$ \\
\hline $12-17$ & 39 & $66 \cdot 7$ & 43.6 & $30 \cdot 8$ \\
\hline $18-23$ & 26 & 61.5 & $76 \cdot 9^{\star \star}$ & $30 \cdot 8$ \\
\hline \multicolumn{5}{|l|}{ Gender of the child } \\
\hline Female & 47 & 48.9 & 48.9 & $19 \cdot 1$ \\
\hline Male & 51 & $60 \cdot 8$ & $56 \cdot 9$ & $35 \cdot 3$ \\
\hline \multicolumn{5}{|l|}{ Breast-feeding } \\
\hline Yes & 80 & $52 \cdot 5$ & $46 \cdot 3$ & $30 \cdot 0$ \\
\hline No & 18 & $66 \cdot 7$ & $83 \cdot 3^{\star \star}$ & $16 \cdot 7$ \\
\hline \multicolumn{5}{|c|}{ Education level of the mother } \\
\hline No formal education & 52 & $53 \cdot 8$ & 51.9 & $28 \cdot 8$ \\
\hline Primary level & 29 & $55 \cdot 2$ & $55 \cdot 2$ & 27.6 \\
\hline Secondary and above & 17 & $58 \cdot 8$ & 52.9 & 23.5 \\
\hline \multicolumn{5}{|c|}{ Household socio-economic quintile } \\
\hline Quintile 1 (poorest) & 20 & $45 \cdot 0$ & $50 \cdot 0$ & $25 \cdot 0$ \\
\hline Quintile 2 & 20 & $45 \cdot 0$ & $55 \cdot 0$ & $30 \cdot 0$ \\
\hline Quintile 3 & 19 & 57.9 & $36 \cdot 8$ & $26 \cdot 3$ \\
\hline Quintile 4 & 23 & 65.2 & $52 \cdot 2$ & $21 \cdot 7$ \\
\hline Quintile 5 (richest) & 16 & 62.5 & 75.0 & 37.5 \\
\hline
\end{tabular}

*MDD, minimum dietary diversity; MMF, minimum meal frequency; MAD, minimum acceptable diet.

${ }^{\star *}$ Significant differences $(P<0.05)$ in proportions for each characteristic using Pearson's chi-square test. 
Table 3 Proportions (\%) of children aged 6-23 months who consumed iron-rich foods in the past $24 \mathrm{~h}$ according to individual, environmental-related factors and household sociodemographic characteristics ( $n$ 98)

\begin{tabular}{|c|c|c|c|}
\hline Variables & $n$ & $\%$ & $P$-value \\
\hline \multicolumn{4}{|c|}{$\begin{array}{l}\text { Psychosocial factors of the mother } \\
\text { Intention score }\end{array}$} \\
\hline 4 & 8 & $50 \cdot 0$ & \multirow[t]{2}{*}{0.343} \\
\hline 5 & 90 & $66 \cdot 7$ & \\
\hline \multicolumn{4}{|c|}{ Perceived behaviour control score } \\
\hline$<20$ & 42 & $69 \cdot 0$ & \multirow[t]{2}{*}{0.500} \\
\hline$\geq 20$ & 56 & 62.5 & \\
\hline \multicolumn{4}{|l|}{ Environmental factors } \\
\hline Household food security le & & & \multirow{5}{*}{0.009} \\
\hline Food-secure & 22 & $81 \cdot 8$ & \\
\hline Mildly food-insecure & 6 & $100 \cdot 0$ & \\
\hline Moderately food-insecure & 8 & 87.5 & \\
\hline Severely food-insecure & 62 & $53 \cdot 2$ & \\
\hline \multicolumn{4}{|c|}{ Number of foods available at community level } \\
\hline$<50$ & 25 & $68 \cdot 0$ & \multirow[t]{2}{*}{0.743} \\
\hline$\geq 50$ & 73 & 64.4 & \\
\hline \multicolumn{4}{|c|}{ Number of foods available at household level } \\
\hline$<4$ & 73 & $63 \cdot 0$ & \multirow[t]{2}{*}{0.415} \\
\hline$>4$ & 25 & $72 \cdot 0$ & \\
\hline \multicolumn{4}{|c|}{ Main way of food acquisition in the household } \\
\hline Purchase & 50 & $72 \cdot 0$ & \multirow[t]{3}{*}{0.356} \\
\hline Family food production & 32 & 59.4 & \\
\hline Food donation & 16 & $56 \cdot 3$ & \\
\hline \multicolumn{4}{|c|}{ Child, mother and household-related factors } \\
\hline Age of the child (months) & & & \\
\hline $6-11$ & 33 & 48.5 & \multirow[t]{3}{*}{0.041} \\
\hline $12-17$ & 39 & $71 \cdot 8$ & \\
\hline $18-23$ & 26 & $76 \cdot 9$ & \\
\hline \multicolumn{4}{|l|}{ Gender of the child } \\
\hline Female & 47 & $63 \cdot 8$ & \multirow[t]{2}{*}{0.768} \\
\hline Male & 51 & $66 \cdot 7$ & \\
\hline \multicolumn{4}{|l|}{ Age of the mother (years) } \\
\hline $15-19$ & 9 & 44.4 & \multirow[t]{4}{*}{0.441} \\
\hline $20-29$ & 48 & $70 \cdot 8$ & \\
\hline $30-39$ & 31 & $61 \cdot 3$ & \\
\hline$\geq 40$ & 10 & $70 \cdot 0$ & \\
\hline \multicolumn{4}{|l|}{ Education level of the mother } \\
\hline No formal education & 52 & $63 \cdot 5$ & 0.563 \\
\hline Primary level & 29 & $62 \cdot 1$ & \\
\hline Secondary and above & 17 & $76 \cdot 5$ & \\
\hline Household size & & & \\
\hline $1-9$ & 33 & $72 \cdot 7$ & 0.372 \\
\hline $10-19$ & 51 & $58 \cdot 8$ & \\
\hline$\geq 20$ & 14 & 71.4 & \\
\hline Gender of head of househo & & & \\
\hline Male & 71 & $69 \cdot 0$ & 0.211 \\
\hline Female & 27 & $55 \cdot 6$ & \\
\hline Education level of head of & eholc & & \\
\hline No formal education & 72 & $69 \cdot 4$ & 0.350 \\
\hline Primary level & 20 & $55 \cdot 0$ & \\
\hline Secondary and above & 6 & $50 \cdot 0$ & \\
\hline Household socio-economic & tile & & \\
\hline Quintile 1 (poorest) & 20 & $60 \cdot 0$ & 0.675 \\
\hline Quintile 2 & 20 & $60 \cdot 0$ & \\
\hline Quintile 3 & 19 & $63 \cdot 2$ & \\
\hline Quintile 4 & 23 & $65 \cdot 2$ & \\
\hline Quintile 5 (richest) & 16 & 81.3 & \\
\hline
\end{tabular}

fit chi-square test and the Hosmer and Lemeshow test. The multi-collinearity assumption was assessed using variance inflation factor values which should be below the recommended cut-off point of $10^{(29)}$. We concluded to a good final model fit when: (a) the $P$ value of chi-square test of the final model was statistically significant $(P<0.05)$; (b) the value of the Hosmer and Lemeshow test for the final model was not statistically significant $(P \geq 0.05)^{(30)}$; (c) when residual statistics namely Cook's distance and DFBeta were below 1; and (d) studentised and standardised residuals values were less than $\pm 2^{(25)}$.

\section{Results}

\section{Sociodemographic characteristics, bousebold food insecurity and mother's psychosocial factors}

Of the total sample initially targeted (103 mothers of children aged 6-23 months), data could not be collected for five mothers because they were absent at the time of the data collection (three) or data were incomplete (two). The mean \pm SD household size was 13.6 \pm 8.6 members. The mean age of the household heads was $53.7 \pm 15.6$ years and $27.6 \%$ were female. Concerning the socio-economic status, $43.9 \%$ of the household were in the lower third of socio-economic score, while $33.7 \%$ were in the higher third of socio-economic score. The mean age of children's mothers was $28 \cdot 3 \pm 7 \cdot 1$ years and about five out of ten had no formal education. Regarding children, $52.0 \%$ were boys and the mean age of the group was $13 \cdot 5 \pm 4.8$ months (Table 4 ).

In the study area, the mean household food insecurity score was $10 \cdot 7 \pm 8 \cdot 1$ out of a maximum of 27 . About $22 \%$ of households were food-secure, while $6 \cdot 1 \%$ were mildly food-insecure, $8.2 \%$ were moderately food-insecure and $63.3 \%$ were severely food-insecure. The mean number of foods recorded at the household level was $2 \cdot 4 \pm 2 \cdot 3$, while at the community level, the mean number of foods recorded in the local shops and public markets was $53 \cdot 0 \pm 6 \cdot 1$ (Table 4).

Overall, the mean score on the intention of mothers to provide IRF to their children was $4.8 \pm 0.5$ out of a maximum of 5 points. Of the ninety-eight mothers, $91.8 \%$ had a score of 5 (strongly agree), $6 \cdot 1 \%$ had a score of 4 (agree), while $1.0 \%$ had either a score of 3 (neither agree, nor disagree) or 2 (disagree). With regard to the PBC, the mean score was $19 \cdot 3 \pm 5 \cdot 2$ out of a maximum value of 25 (data not shown).

\section{Infant and young child feeding practices}

In children aged 12-15 months, the proportion of continued breast-feeding at 1 year of age was 93.1\% (27/29), while amongst children aged 6-8 months, the rate of introduction of solid, semi-solid or soft foods was $94.4 \%$ (17/18). Regarding food groups consumed by children the day before the survey, foods from the grains, roots, and tubers group and from the vitamin A-rich fruits and vegetables group were consumed by about eight out of ten children, while about two-thirds had eaten meat and dairy products (Table 1). Roughly one-fifth had consumed foods from the other fruits and vegetables group, while eggs and foods 


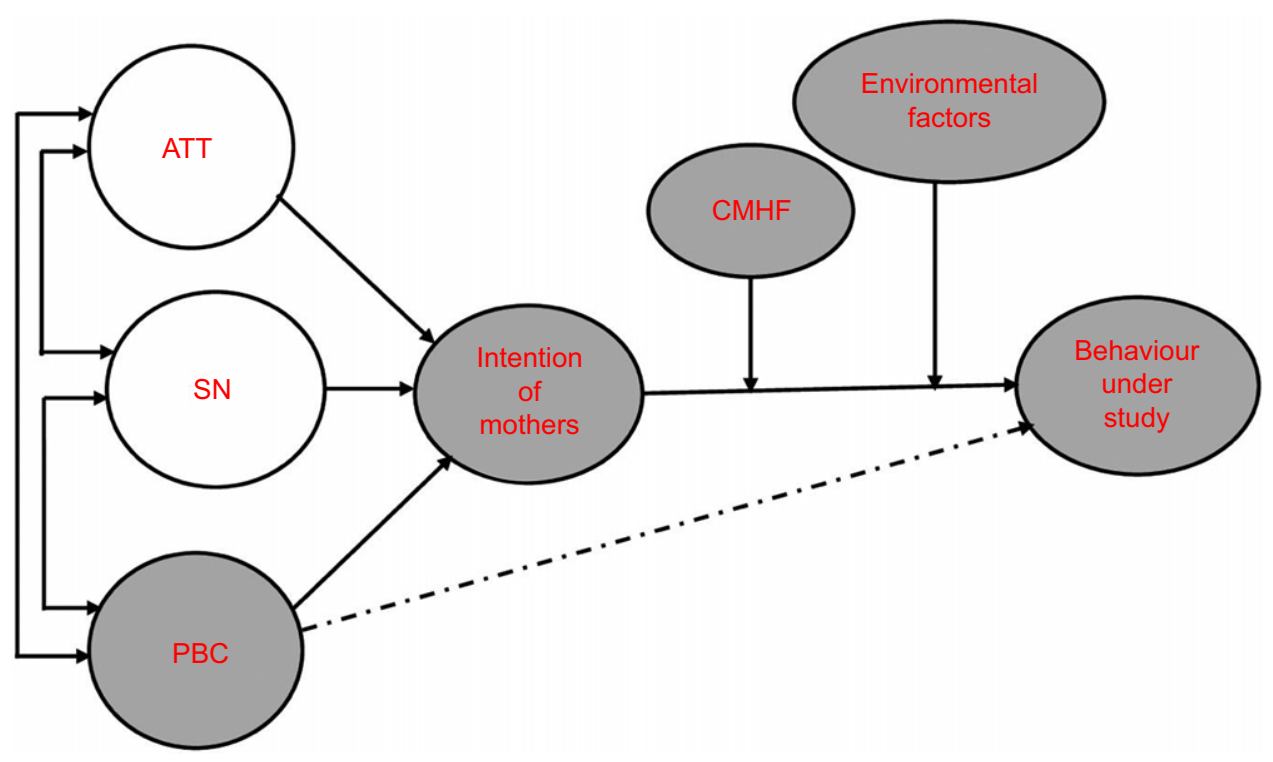

Fig. 1 (colour online) Diagram of TPB constructs along with external factors tested as predictors of the behaviour under study*. ${ }^{*}$ Factors in shaded circles were used in the analysis of prediction of the behaviour under study. TPB, Theory of Planned Behaviour; ATT, attitude; SN, subjective norm; PBC, perceived behavioural control; CMHF, child, mother and household-related factors. Environmental factors: number of foods available at household level; number of foods available at community level; household food insecurity; main way of household's food acquisition

Table 4 Sociodemographic characteristics of the sample $(n 98)$

\begin{tabular}{|c|c|c|c|}
\hline Characteristics & $\%$ & Mean & SD \\
\hline Age (months) of the child & & $13 \cdot 5$ & $4 \cdot 8$ \\
\hline \multicolumn{4}{|l|}{ Child's gender } \\
\hline Boys & $52 \cdot 0$ & & \\
\hline \multirow{2}{*}{\multicolumn{4}{|c|}{ Gender of $\mathrm{HH}$ head }} \\
\hline & & & \\
\hline Male & $72 \cdot 4$ & & \\
\hline Female & $27 \cdot 6$ & & \\
\hline Age (years) of $\mathrm{HH}$ head & & 53.7 & $15 \cdot 6$ \\
\hline \multicolumn{4}{|l|}{ Education level of $\mathrm{HH}$ head } \\
\hline None & 73.5 & & \\
\hline Primary & $20 \cdot 4$ & & \\
\hline Middle or higher & $6 \cdot 1$ & & \\
\hline HH size & & $13 \cdot 6$ & 8.6 \\
\hline Age (years) of child's mother & & $28 \cdot 3$ & $7 \cdot 1$ \\
\hline \multicolumn{4}{|l|}{ Education level of child's mother } \\
\hline None & $53 \cdot 1$ & & \\
\hline Primary & $29 \cdot 6$ & & \\
\hline Middle or higher & $17 \cdot 3$ & & \\
\hline $\mathrm{HH}$ food insecurity score & & $10 \cdot 7$ & $8 \cdot 1$ \\
\hline Food security & 22.4 & & \\
\hline Mild food insecurity & $6 \cdot 1$ & & \\
\hline Moderate food insecurity & $8 \cdot 2$ & & \\
\hline Severe food insecurity & 63.3 & & \\
\hline Number of foods available at $\mathrm{HH}$ level & & $2 \cdot 4$ & $2 \cdot 3$ \\
\hline Number of foods available at community level & & $53 \cdot 0$ & $6 \cdot 1$ \\
\hline $\mathrm{HH}$ socio-economic score & & -0.01 & 9.2 \\
\hline Lower third $(-1.3$ to -0.4$)$ & $43 \cdot 9$ & & \\
\hline Medium third $(-0.3$ to 0.6$)$ & 24.4 & & \\
\hline Higher third $(0.7$ to +1.3$)$ & $33 \cdot 7$ & & \\
\hline
\end{tabular}

$\mathrm{HH}$, household.

from the legumes and nuts group were the least consumed by children. There were no significant differences between age groups or breast-feeding status with regard to proportions of children consuming foods from the different food groups, except for flesh foods for which a significant difference $(P=0.041)$ between age groups of the children was observed. There was also no significant difference in proportions of children being breastfed or not with regard to the consumption of IRF the day before the study $(77.8 \%$ v. $62 \cdot 5 \%, P=0.219)$.

Amongst all children aged 6-23 months, proportions fed with the MDD and the MMF were, respectively, 55.1\% and $53.1 \%$, while $27.6 \%$ benefited from the MAD. Differences were observed between age groups with regard to MDD $(P=0.027)$ and MMF $(P=0.017)$ (Table 2$)$. In addition, the proportion of not-breastfed children benefiting from the MMF ( $83.3 \%)$ was higher than that ( $46.3 \%)$ of breastfed children $(P=0 \cdot 004)$. There were no differences in proportions of children meeting criteria for MMF, MAD and MDD according to their gender, the education level of the mother or household socio-economic quintiles.

\section{Provision of iron-rich foods and its predictors}

Overall, $65.3 \%$ of children aged 6-23 months were fed IRF the day preceding the survey. By also considering children 6-23 months fed with Fe-fortified foods (16.3\%), a total of $67.3 \%$ of children aged $6-23$ months were fed IRF or Fe-fortified foods in the previous $24 \mathrm{~h}$. Regarding the types of IRF that were consumed by young children, $65.3 \%$, $9.2 \%, 4.1 \%$ and $2.0 \%$ received, respectively, fish, eggs, meat and liver/organ meats. None had consumed poultry. Overall, the proportion of children aged 6-11 months who had consumed IRF the day before the survey (48.5\%) was lower than that (about $74.4 \%$ ) amongst older children (Table 3). Furthermore, about half of children aged 6-23 months living in severely food-insecure households 
Table 5 Binary logistic regression of predictors of the daily consumption of iron-rich foods among children 6-23 months old ( $n$ 98)

\begin{tabular}{|c|c|c|c|c|c|}
\hline \multirow[b]{2}{*}{ Independent variables } & \multirow[b]{2}{*}{ Coefficients } & \multirow[b]{2}{*}{ SE } & \multicolumn{3}{|c|}{$95 \% \mathrm{Cl}$ for OR } \\
\hline & & & Lower & OR & Upper \\
\hline \multicolumn{6}{|l|}{ Bloc 1} \\
\hline Age of the child & $0 \cdot 10^{*}$ & 0.05 & 1.01 & $1 \cdot 11$ & $1 \cdot 22$ \\
\hline \multicolumn{6}{|l|}{ Bloc 2} \\
\hline Age of the child & $0.13^{*}$ & 0.05 & 1.03 & 1.14 & 1.26 \\
\hline Number of foods available at community level & $-0.07^{*}$ & 0.04 & 0.86 & 0.93 & 1.00 \\
\hline Number of foods available at household level & 0.15 & 0.13 & 0.90 & $1 \cdot 16$ & 1.50 \\
\hline Ways of food acquisition in the household & -0.09 & 0.36 & 0.45 & 0.91 & 1.86 \\
\hline \multicolumn{6}{|l|}{ Bloc 3} \\
\hline Age of the child & $0 \cdot 13^{*}$ & 0.05 & 1.03 & $1 \cdot 14$ & $1 \cdot 27$ \\
\hline Number of foods available at community level & -0.06 & 0.04 & 0.88 & 0.96 & 1.02 \\
\hline Number of foods available at household level & -0.02 & 0.15 & 0.73 & 0.98 & 1.31 \\
\hline Main way of food acquisition in the household & 0.04 & 0.37 & 0.51 & 1.04 & $2 \cdot 13$ \\
\hline Household food security score & $-0.22^{*}$ & 0.09 & 0.68 & 0.80 & 0.96 \\
\hline \multicolumn{6}{|l|}{ Bloc 4} \\
\hline Age of the child & $0.13^{*}$ & 0.05 & 1.03 & 1.14 & $1 \cdot 26$ \\
\hline Number of foods available at community level & -0.06 & 0.04 & 0.88 & 0.95 & 1.02 \\
\hline Number of foods available at household level & -0.02 & 0.15 & 0.73 & 0.98 & 1.32 \\
\hline Main way of food acquisition in the household & 0.03 & 0.38 & 0.49 & 1.03 & $2 \cdot 17$ \\
\hline Household food security score & $-0.22^{*}$ & 0.09 & 0.68 & 0.80 & 0.96 \\
\hline Intention & -0.04 & 0.49 & 0.37 & 0.96 & 2.49 \\
\hline Perceived behaviour control & 0.00 & 0.05 & 0.92 & 1.00 & $1 \cdot 10$ \\
\hline
\end{tabular}

$R^{2}=0.15$ (Hosmer and Lemeshow), 0.17 (Cox and Snell) and 0.24 (Nagelkerke). Model $\chi^{2}(7)=18.59 . P=0.010 .{ }^{\star} P<0.05$.

were fed IRF, compared to more than $80.0 \%$ of children living in a food-secure household or a mildly or moderately food-insecure household (Table 3). There were no differences in proportions of children who had consumed IRF according to mother's psychosocial factors as well as to her level of education or age, neither with regard to household sociodemographic characteristics (Table 3).

Table 5 presents the results of logistic regression analyses. In bloc 1 , the age of the child was a significant determinant of the provision of IRF (OR $=1 \cdot 11,95 \% \mathrm{CI}$ $(1 \cdot 02,1 \cdot 22))$. In bloc 2 , none of the added variables, namely the number of foods available at household and community level as well as the main way of food acquisition by household, was a significant determinant of the provision of IRF, but the age of the child was still a significant predictor of the behaviour under study (OR $=1 \cdot 14,95 \%$ $(1.03,1.26))$. In bloc 3 , household food insecurity $(\mathrm{OR}=0.80,95 \% \mathrm{CI}(0.68,0.96))$ and the age of the child $(\mathrm{OR}=1 \cdot 14,95 \% \mathrm{CI}(1.03,1.27))$ were both found to be significant predictors of the provision of IRF. Finally, in bloc 4, the intention of the mother to provide IRF as well as her PBC were added but not found to be significant determinants of the provision of IRF to children aged 6-23 months, while household food insecurity $(\mathrm{OR}=0.80,95 \% \mathrm{CI}(0.68,0.96))$ and the age of the child $(\mathrm{OR}=1.14,95 \% \mathrm{CI}(1.03,1.26))$ remained significant. The final model explained $24.0 \%\left(R^{2}\right.$ Nagelkerke $)$ of the variance associated with the provision of IRF to children aged 6-23 months. Criteria to assess the final model fit were respected: the chi-square test was significant $(P=0.010)$ and the result of the Hosmer and Lemeshow test was not significant $(P=0.538)$. All variance inflation factor values were also below 10. Residual statistics namely Cook's distance was below 1 and all DFBetas values, except for one observation of DFBeta for the constant, were below 1. All studentised residuals had values between $+/-2$, while one observation has standardised residual above $+/-2$.

\section{Discussion}

In low- and middle-income countries, feeding practices amongst children aged 6-23 months are of concern and constitute a major constraint for their optimal nutritional status, growth and development ${ }^{(31-33)}$. In this paper, feeding practices amongst a group of children aged 6-23 months living in Matam region, Senegal, are described including their consumption of IRF given their key role in the prevention of anaemia, a public health concern in the country. Thereafter, the relationship between the child's consumption of IRF, mother's psychosocial factors to provide him IRF, food environmental factors and sociodemographic characteristics were investigated.

First, foods from the grains, roots and tubers group and vitamin A-rich fruits and vegetables group were those eaten by the largest proportions ( $80.6 \%$ and $77.6 \%$, respectively) of children aged 6-23 months, followed by flesh foods $(65.3 \%)$ and dairy products (63.3\%). Eggs were less consumed amongst the seven food groups. In the current research $(80.6 \%)$ as well as the latest DHS national data $(90.0 \%)^{(3)}$, grains, roots and tubers were the most consumed food groups by the children in the past $24 \mathrm{~h}$. The young child's diet appears to look like the typical meal in Senegal composed of rice, the staple food to which is added a sauce, with or without meat and vegetables. Moreover, some beliefs of mothers likely guided the choice 
of food provided to young children. A study carried out in the St-Louis region (northern Senegal) revealed that soft foods such as porridges and milk may be considered more suitable for children aged 6-8 months, while for those aged 9-12 months, rice and larger quantities of foods would be thought to be more appropriate ${ }^{(34)}$.

Furthermore, the latest data from the Senegal $\mathrm{DHS}^{(3)}$ had reported that only $7.3 \%$ of children in the Matam region benefited from a MAD which is lower than in our group (27.6\%). Proportions of children fed with appropriate MDD and provided with the recommended MMF were also much higher in our study $(55.1 \%$ and $53.1 \%)$ as compared to DHS data for the Matam region $(21.1 \%$ and $33.2 \%$ for MDD and MMF respectively) $)^{(3)}$. Other positive feeding practices were also noticed in the present study: similarly to DHS data for Matam, over $90.0 \%$ of children were breastfed at 1 year and a higher proportion received complementary foods between 6 and 8 months of age $(94.4 \%$ in this study $v .67 \cdot 0 \%$ in DHS) as well as IRF $(65 \cdot 3 \% v .53 \cdot 1 \%)^{(3)}$.

Discrepancies between the two sets of data (ours and regional data from the Senegal 2018 DHS) might be attributed to different factors. First, the time frame was different: DHS data ${ }^{(3)}$ were collected from March to December which includes the rainy season period (July to August) while for this study, data on IYCF practices were collected in January and February, a period of the year when food shortage in Matam region is generally less of an issue ${ }^{(18)}$ and during which food prices appear to be the lowest ${ }^{(35)}$. Secondly, the sampling method may be another factor. The sampling method between the two studies was different: a stratified two-stage cluster design was used in the 2018 DHS, while a random sampling of four out of all villages and twenty-five or twenty-six of all households with children aged 6-23 months located in these villages were invited to participate to the present study. Finally, the DHS sample size was slightly higher than ours $(127 v .98)^{(3)}$.

In the current study, there was no relationship between the mothers' intention to give IRF to children aged 6-23 months, nor between their PBC and the actual provision of IRF to their children. This lack of relationship is not in line with findings from other studies conducted in developed countries. For instance, amongst rural American primiparous mothers, a strong intention $(\mathrm{OR}=1.89)$ and higher levels of self-efficacy at 2 weeks after the birth $(\mathrm{OR}=1.04)$ were significantly $(P<0.05)$ associated with an increased probability of breast-feeding for 6 months ${ }^{(36)}$. In Australia, mothers' intention was associated with the introduction of solid foods at 6 months ${ }^{(37)}$, while in Scotland, using an extended TPB, McMilan and colleagues $^{(38)}$ found that intention was a significant and positive predictor of breast-feeding at birth $(\beta=0.85$, $P<0.001)$, at discharge from hospital $(\beta=0.83, P<0.001)$ and $10 \mathrm{~d}$ after discharge $(\beta=0.42, P<0.05)^{(38)}$. Several reasons could explain the absence of a relationship between the mother's intention to provide IRF to her child and his/her child's actual consumption of IRF in this research.
First, the strength of the intention may have been overestimated. It is possible that when answering the questionnaire on psychosocial factors, mothers wanted to demonstrate a positive image of their intended behaviour towards their young child or just to please enumerators, even if precautions were taken to reduce social desirability during data collection. For instance, before administrating the questionnaire, a statement was read to each participating mother about the fact that she was free to answer or not to questions and that there was no 'good' or 'wrong' answer. Additionally, visual scales with pictograms were used to help participants get a better understanding of questions. Yet, we believe that another factor may better explain the gap between intention and behaviour in the present study. Indeed, the formulation of items in the questionnaire related to the intention of performing the behaviour under study ('I intend to give IRF at least once a day to my child aged 6-23 months' and ' $I$ will give IRF at least once a day to my child aged 6-23 months') may have been misunderstood by some mothers. As such, when asking the mother of a child aged 7 months if she intended to provide IRF daily to her child aged 6-23 months, she might have thought that she was asked about her 'overall intention' to provide IRF daily to her child somewhere in time before he/she reaches 23 months of age rather than her 'present intention' to do so. Moreover, during FGD held to develop the questionnaire on psychosocial factors, the age of the child was mentioned as a potential barrier to the provision of IRF. Some mothers stated that 'it is too early to give IRF to children aged 6 months old' (unpublished results). A study conducted in rural Senegal revealed that most mothers start introducing animal-source foods to the diet of children at the age of 10 months ${ }^{(39)}$. Interestingly, in our case, even though almost all children aged 6-8 months were receiving complementary foods, a much smaller proportion was consuming IRF ( $44.4 \%$ or $8 / 18, v .65 .3 \%$ in the whole sample). Hence, despite the strong intention to provide IRF to children aged 6-23 months, fewer children aged 6-11 months were fed with these foods compared to children aged 12-17 months and 18-23 months, suggesting that mothers take the child's age in consideration before giving them IRF, as also reported by Zobrist et al. ${ }^{(34)}$. In their research, animal-source proteins (e.g. meat, chicken, fish and goats), considered by mothers as heavy foods (or difficult to digest), were still considered good for the child but older age groups ${ }^{(34)}$.

In the multi-level logistic regression analyses conducted in this study, the age of the child was consistently and positively associated with the provision of IRF or in other words, the older the child was, the more he/she was likely to consume IRF. This result concurs with the Senegal 2018 DHS data which show that the consumption of IRF increased with child's age: from $12 \cdot 1 \%$ at $6-8$ months to $62.0 \%$ at $18-23$ months $^{(3)}$. Based on the theoretical framework used in the present study (an extended version of the TPB), the child's age emerges as an external factor that would impact the mother's behaviour through moderation, 
as it seems to influence the relation between intention and behaviour.

Besides child's age that is a personal factor, another external factor, and this time an environmental one, was shown to be a determinant of the provision of IRF to young children: the household's level of food insecurity. Indeed, household food insecurity status was negatively associated with the consumption of IRF. The negative relationship between household food insecurity and child feeding practices has also been reported in Ghana ${ }^{(40)}, \mathrm{Nepal}^{(41)}$, Kenya $^{(42)}$ and in Bangladesh ${ }^{(43)}$. For instance, in Ghana, Agbadi and colleagues ${ }^{(40)}$ observed that children who lived in food-secure households were significantly more likely than children in food-insecure households to receive recommended MAD (OR $=0.53 ; 95 \% \mathrm{CI}(0.35,0.82)$ ). Similarly, in Kenya, infants living in food-secure households were twice as likely to benefit from appropriate feeding practices (or the MAD) than those from food-insecure households $(\mathrm{AOR}=2.35, P=0.008)^{(42)}$. It is likely that food-secure households had better access to foods and thus better chances to provide young children with IRF. In fact, in a previous paper, we have shown that the number of foods available in the household and its socio-economic status were positively associated with household food security ${ }^{(13)}$. In this study, as was the case with child's age, the household food insecurity status seemingly acted as a moderator, impeding the passage between the mother's intention and the behaviour of providing IRF to her child.

This raises the question of how can we get mothers to ensure that when children are introduced to complementary foods at 6 months, IRF will necessarily be part of it? From our results, it seems that to help mothers introducing IRF to their children from the age of 6 months, nutrition intervention programmes at the community level should be designed in two ways: first, by combating the belief that foods rich in Fe should be given at a later age than other complementary foods and second, by enhancing environmental conditions to improve their household access to foods and, in particular, to IRF. For example, home visits to reach mothers and families before children are 6 months old could help promote the introduction of complementary foods, especially IRF, from the age of 6 months. Also, during immunisation visits at the health centres when children are aged 5 months, a nutrition education session and/or counselling on the importance of introducing IRF at the age of 6 months could be offered to mothers. Persons or groups of persons close to mothers who influence infant feeding practices may also be targeted by these activities. Furthermore, given the low number of available foods at the household level in the study setting, it would seem helpful that the Senegal National Strategy on Food Security and Resilience focuses on improving household income, so families would be more likely to afford IRF.

Finally, it should be noted that only $24 \%$ of the variance of behaviour studied was explained by the extended version of TPB used in the current research. This situation may be due to the following reasons. First, the TPB itself has some limits in predicting a behaviour ${ }^{(44,45)}$, as studies using this theory showed a gap between the intention and the behaviour $^{(44,46)}$. For instance, a meta-analysis revealed that the TPB accounted for $27 \%$ of the variance in behaviours ${ }^{(44)}$. Moreover, an extended version of TPB to predict mothers' decisions to introduce complementary feeding at 6 months has explained about $30 \%$ of the variance in behaviour $^{(37)}$. Furthermore, another reason is related to the relatively low number of external factors added to the TPB in this study. Only four food environment factors were included in the extended version. Amongst these, only household food insecurity status was significant in predicting the behaviour studied. Therefore, it would have been interesting to add more food environment factors such as food preferences, acceptability and affordability $^{(47)}$ into the model, perhaps the variance of behaviour predicted might have improved.

The current study has some weaknesses that should be acknowledged. First, its cross-sectional nature makes it difficult to conclude that the results from this research represent that of an entire year, due to seasonal variability in terms of food availability. The current study was conducted during a period of food abundance. Therefore, it should be interesting that future research should be carried out in lean season in order to complement the results of the current study. Furthermore, although villages and households were randomly selected, the fact that we have chosen by convenience two departments out of three means that we cannot claim the representativeness of results to the entire region of Matam. A cluster sampling of households would also have allowed us to obtain better representativeness of the population of children aged 6-23 months in the study setting.

Another weakness of this research is related to the measurement of IRF consumption which did not allow us to capture the amount of IRF consumed by children, although the utilisation of the same questionnaire as that used for the Senegal DHS allowed us to compare our findings with country data. Despite these limitations, this research is innovative in examining the contribution of psychosocial, food environmental factors and child's characteristics in predicting rural Senegalese mothers' behaviour of providing IRF to their children aged 6-23 months. For the first time, an extended theory of prediction has been used to test which factors are determinants in the provision of IRF to children during the critical window of age of 6-23 months in the Matam area. Therefore, the current study gave a better insight about predictors of mothers' provision of IRF to their children aged 6-23 months in the study area.

\section{Conclusions}

Although mothers in the study setting did have the intention to provide IRF to their young child, external factors 
such as a younger child's age and household food insecurity increased the likelihood for children of not being provided with these foods. More research is certainly needed to investigate other environment-related factors such as desirability and acceptability of food that may also impact the provision of IRF to young children. Nevertheless, when promoting children's IRF consumption, more attention should be given to household food insecurity and child characteristics (age) in the research area. In the future, targeting behaviour change interventions to mothers before their children reach the age of 6 months could be efficient to improve the provision of IRF to young children and ensure that these foods are provided timeously. Moreover, efforts could certainly be undertaken to increase the household socio-economic level to facilitate its access to foods in particular to IRF. To do so, the implementation of measures included in the national strategy on food security and resilience ${ }^{(48)}$ which relate to the improvement of socio-economic conditions of households would be valuable.

\section{Acknowledgements}

Acknowledgements: We are sincerely grateful to all participants for their contribution to this research. We are particularly thankful to Professor Mohamadou Sall, Director of the Institut de Population, Développement et Santé de la Reproduction (IPDSR) of the Cheick Anta Diop University, Dakar, Senegal, for his insightful comments and supports throughout this research. We gratefully acknowledge statistical advices from Dr Jérémie B. Dupuis at Moncton University. We are also thankful to all enumerators who were involved in the data collection and analyses as well as to students of the IPDSR who dedicated part of their time to the questionnaire development process. Financial support: We would like to acknowledge the financial contribution of the International Development Research Center (IDRC) and the Social Sciences and Humanities Research Council of Canada (SHRC) which supported this research through the Queen Elizabeth Scholarship programme. Conflict of interest: There are no conflicts of interest. Authorship: The study was designed together by the three authors (I.G., S.B. and K.A.) of the paper. K.A. formulated the research questionnaires and questionnaires were reviewed by I.G., S.B. and K.A. Study preparation, data collection and analyses were made by K.A. The paper was written by K.A. and it was reviewed several times with I.G. and S.B. Ethics of human subject participants: This study was conducted according to the guidelines laid down in the Declaration of Helsinki and all procedures involving research study participants were approved by the Comité d'Éthique de la Recherche de l'Université Laval (CERUL) and the Comité National d'Éthique pour la Recherche en Santé (CNERS) of
Senegal. Written informed consent was obtained from all subjects.

\section{Supplementary material}

For supplementary material accompanying this paper visit https://doi.org/10.1017/S1368980021002718

\section{References}

1. World Health Organization (WHO) (2015) The Global Prevalence of Anaemia in 2011. Geneva: WHO.

2. World Health Organization (WHO) (2017) Nutritional Anaemias: Tools for Effective Prevention and Control. Geneva: WHO.

3. Agence Nationale de la Statistique et Démographie et ICF (2018) Sénégal: Enquête Démographique et de Santé Continue (EDS-Continue 2017). Dakar, Sénégal \& Rockville, MD, USA: ANSD et ICF International.

4. United Nations International Children's Emergency Fund (UNICEF) (1990) Strategy for Improved Nutrition of Children and Women in Developing Countries. New York: UNICEF.

5. Bhutta ZA, Ahmed T, Black RE et al. (2008) What works? Interventions for maternal and child undernutrition and survival. Lancet 371, 417-440.

6. Bhutta ZA, Das JK, Rizvi A et al. (2013) Evidence-based interventions for improvement of maternal and child nutrition: what can be done and at what cost? Lancet 382, 452-477.

7. Food and Agriculture Organization of the United Nations (FAO) (1996) Rome Declaration on World Food Security and World Food Summit Plan of Action. Rome: FAO.

8. Engle P, Lhotská L \& Armstrong H (1997) The Care Initiative: Assessment, Analysis and Action to Improve Care for Nutrition. New York: UNICEF.

9. United Nations International Children's Emergency Fund (UNICEF) (2019) The State of the World's Children 2019 - Children, Food and Nutrition: Growing Well in a Changing World. New York: UNICEF.

10. Programme Alimentaire Mondial (PAM) (2014) Analyse Globale de la Vulnérabilité, de la Sécurité Alimentaire et de la Nutrition (AGVSAN). Dakar: PAM.

11. Dewey K (2003) Guiding Principles for Complementary Feeding of the Breastfed Child. Washington, DC, USA: PAHO/WHO, Division of Health Promotion and Protection/ Food and Nutrition Program.

12. World Health Organization (WHO) (2005) Guiding Principles for Feeding Non-Breastfed Children 6-24 Months of Age. Geneva: WHO.

13. Akpaki K, Galibois I, Sall M et al. (2020) Assessing the food availability and food insecurity situation among communities of Matam Region, Senegal. Ecol Food Nutr. Published online: 09 March 2020. doi: 10.1080/03670244.2020.1733993.

14. Godin G (2012) Les Comportements Dans Le Domaine De La Santé: Comprendre Pour Mieux Intervenir. Montréal: Presses de l'Université de Montréal.

15. World Health Organization (WHO) (2010) Indicators for assessing infant and young child feeding practices: part 2: measurement. Geneva: WHO; available at https://apps. who.int/iris/bitstream/handle/10665/44306/9789241599290_ eng.pdf (accessed July 2018).

16. Ajzen I (1991) The theory of planned behavior. Organ Behav Hum Decis Process 50, 179-211. 
17. Ajzen I \& Madden TJ (1986) Prediction of goal-directed behavior: attitudes, intentions, and perceived behavioral control. J Exp Soc Psychol 22, 453-474.

18. Service Régional de la Statistique et de la Démographie (2015) Situation économique et sociale régionale de Matam 2013. www.ansd.sn/ressources/ses/SES-Matam-2013. pdf (accessed July 2017).

19. Faul F, Erdfelder E, Buchner A et al. (2009) Statistical power analyses using $G^{*}$ power 3.1: tests for correlation and regression analyses. Behav Res Methods 41, 1149-1160.

20. Faul F, Erdfelder E, Lang A-G et al. (2007) G* power 3: a flexible statistical power analysis program for the social, behavioral, and biomedical sciences. Behav Res Methods 39, 175-191.

21. Coates J, Swindale A \& Bilinsky P (2007) Housebold Food Insecurity Access Scale (HFIAS) for Measurement of Household Food Access: Indicator Guide (V. 3). Washington, DC: Food and Nutrition Technical Assistance Project, Academy for Educational Development.

22. Gagné C \& Godin G (1999) Les Théories Sociales Cognitives: Guide Pour La Mesure Des Variables Et Le Développement De Questionnaire. Québec: Groupe de recherche sur les aspects psychosociaux de la santé, École des sciences infirmières, Université Laval.

23. Ajzen I (2006) Constructing a Theory of Planned Behavior Questionnaire. Amherst, MA: University of Massachusetts; available at http://people.umass.edu/ aizen/pdf/tpb.measurement.pdf (accessed July 2019).

24. Rabiee F (2004) Focus-group interview and data analysis. Proc Nutr Soc 63, 655-660.

25. Field A (2009) Discovering Statistics Using SPSS: (And Sex and Drugs and Rock'n'Roll), 3rd ed. CA, USA: Sage Publications, Inc.

26. Callender JC \& Osburn H (1979) An empirical comparison of coefficient alpha, Guttman's lambda-2, and MSPLIT maximized split-half reliability estimates. $J$ Educ Meas $\mathbf{1 6}$, 89-99.

27. Guttman L (1945) A basis for analyzing test-retest reliability. Psychometrika 10, 255-282.

28. World Health Organization (WHO) (2008) Indicators for Assessing Infant and Young Child Feeding Practices Part I: Definition. Geneva: WHO; available at https://apps.who. int/iris/bitstream/handle/10665/43895/9789241596664_eng. pdf?sequence $=1$ (accessed July 2018).

29. Gareth J, Witten D, Hastie T et al. (2014) An Introduction to Statistical Learning: With Applications in R. New York, USA: Springer.

30. Hosmer DW, Hosmer T, Le Cessie S et al. (1997) A comparison of goodness-of-fit tests for the logistic regression model. Stat Med 16, 965-980.

31. Gebremedhin S (2019) Core and optional infant and young child feeding indicators in sub-Saharan Africa: a crosssectional study. BMJ Open 9, e023238.

32. Issaka AI, Agho KE, Page AN et al. (2015) Determinants of suboptimal complementary feeding practices among children aged 6-23 months in seven francophone West African countries. Matern Child Nutr 11, 31-52.
33. Lutter CK, Daelmans BM, de Onis M et al. (2011) Undernutrition, poor feeding practices, and low coverage of key nutrition interventions. Pediatrics 128, e1418-e1427.

34. Zobrist S, Kalra N, Pelto G et al. (2017) Results of applying cultural domain analysis techniques and implications for the design of complementary feeding interventions in northern Senegal. Food Nutr Bull 38, 512-527.

35. Programme Alimentaire Mondial (PAM) (2018) Analyse Rapide De La Sécurité Alimentaire Au Nord Du Sénégal. Dakar: PAM

36. Wilhelm SL, Rodehorst TK, Stepans MBF et al. (2008) Influence of intention and self-efficacy levels on duration of breastfeeding for Midwest rural mothers. Appl Nurs Res 21, 123-130.

37. Hamilton K, Daniels L, White KM et al. (2011) Predicting mothers' decisions to introduce complementary feeding at 6 months. An investigation using an extended theory of planned behaviour. Appetite 56, 674-681.

38. McMillan B, Conner M, Woolridge M et al. (2008) Predicting breastfeeding in women living in areas of economic hardship: explanatory role of the theory of planned behaviour. Psychol Health 23, 767-788.

39. Traoré SG, Fokou G, Ndour AP et al. (2018) Assessing knowledge, beliefs and practices related to the consumption of sheep and goat meat in Senegal. Glob Food Sec 19, 64-70.

40. Agbadi P, Urke HB \& Mittelmark MB (2017) Household food security and adequacy of child diet in the food insecure region north in Ghana. PLoS One 12, e 0177377.

41. Osei A, Pandey P, Spiro D et al. (2010) Household food insecurity and nutritional status of children aged 6 to 23 months in Kailali District of Nepal. Food Nutr Bull 31, 483-494.

42. Macharia T, Ochola S, Mutua M et al. (2018) Association between household food security and infant feeding practices in urban informal settlements in Nairobi, Kenya. $J$ Dev Orig Health Dis 9, 20-29.

43. Ali NB, Tahsina T, Hoque DME et al. (2019) Association of food security and other socio-economic factors with dietary diversity and nutritional statuses of children aged 6-59 months in rural Bangladesh. PLoS One 14, e0221929.

44. Armitage CJ \& Conner M (2001) Efficacy of the theory of planned behaviour: a meta-analytic review. $\mathrm{Br} J$ Soc Psychol 40, 471-499.

45. Godin G \& Kok G (1996) The theory of planned behavior: a review of its applications to health-related behaviors. $\mathrm{Am}$ $J$ Health Promot 11, 87-98.

46. Godin G \& Conner M (2008) Intention-behavior relationship based on epidemiologic indices: an application to physical activity. Am J Health Promot. Published online: 01 January 2008. doi: 10.4278/ajhp.22.3.180.

47. Turner C, Aggarwal A, Walls H et al. (2018) Concepts and critical perspectives for food environment research: a global framework with implications for action in low-and middle-income countries. Glob Food Sec 18, 93-101.

48. Secrétariat Exécutif du Conseil National de Sécurité Alimentaire (2015) Stratégie nationale de sécurite alimentaire et de résilience 2015-2035. http://extwprlegs1.fao.org/docs/ pdf/Sen173610.pdf (accessed October 2020). 